\title{
El grabado en madera como arte tocable. Edgardo Antonio Vigo y el Museo de la Xilografía de La Plata
}

\author{
Silvia Dolinko \\ Universidad Nacional de San Martín / \\ CONICET
}

\begin{abstract}
Resumen
El artista platense Edgardo Antonio Vigo mantuvo a lo largo de su trayectoria algunas inquietudes que articularon su labor creativa individual con la esfera de lo social, como la posibilidad del intercambio y la aspiración a una circulación artística extendida. Su voluntad de propugnar un acceso amplio y desacralizado a la obra de arte fue vehiculizado en gran medida a través de distintos proyectos gráficos; entre ellos, la propuesta del Museo de la Xilografía de La Plata fue la que tuvo mayor continuidad en el tiempo. Edición, circulación e intercambio fueron los ejes del programa de ese museo circulante albergado en cajas-valija que le permitía trasladar la colección de grabados a distintos ámbitos, públicos o privados. Las estampas originales y múltiples de su patrimonio resultan así un buen ejemplo de lo que Vigo propuso como «arte tocable».
\end{abstract}

Palabras clave
$\cdot$ grabado · edición · circulación

\begin{abstract}
During his career, the artist from La Plata Edgardo Antonio Vigo maintained some interests such as the possibility of exchange and the aspiration to an extended artistic circulation that assembled his individual creative work with the social sphere. His will to support a wide and demystified access to works of art was transmitted, to a large extent, through different graphic projects, including the proposal of The Museum
\end{abstract}

\footnotetext{
- Doctora en Historia y Teoría del Arte por la Universidad de Buenos Aires. Investigadora del CONICET. Directora de la Maestría en Historia del Arte Argentino y Latinoamericano del Instituto de Altos Estudios Sociales de la Universidad Nacional de San Martín (IDAES-UNSAM) y profesora de Arte argentino y americano del siglo XX en esa institución. Coordinadora general del Instituto de Artes Mauricio Kagel de la UNSAM. Autora de Arte plural. El grabado entre la tradición y la experimentación 1955-1973 (Edhasa, 2012) y editora de Travesías de la imagen. Historias de las artes visuales en la Argentina (CAIA-Eduntref, dos volúmenes, 2011-2012), entre otros libros.
} 
of Xylography of La Plata which was the one with the greatest continuity over time. Edition, circulation and exchange were the central concepts of the program of that itinerant museum held in boxes-suitcase that allowed him to move the collection of engravings to different public or private contexts.

The numerous and original engravings of his patrimony are thus a good example of what Vigo proposed as "touchable art».

\section{Key words}

- printmaking · edition · dissemination

Las polifacéticas intervenciones que Edgardo-Antonio Vigo desplegó en su prolífica trayectoria artística activaron la construcción de la imagen de un artista provocativo, lúdico, experimental y a la vez profundamente comprometido con la intervención social. A lo largo de toda su producción, Vigo mantuvo algunas inquietudes que articularon su labor creativa individual con la esfera de lo social: la voluntad de expandir el acceso al arte, la posibilidad del intercambio y de la participación, el gusto por lo marginal o contracultural junto con el interés por las vanguardias, su atracción por el hecho artesanal, la aspiración a una circulación artística extendida. En particular, su voluntad de propugnar un acceso amplio y desacralizado a la obra de arte fue vehiculizado en gran medida a través de distintos proyectos gráficos.

Considerando las prácticas que Vigo desarrolló dentro de lo que podría considerarse un universo gráfico en sentido amplio, puede destacarse su renovación del centenario grabado en madera, su edición de revistas artesanales, su rol pionero del arte correo, su impulso del «sellado a mano», su obra como autor de poemas matemáticos y de poesía visual. Pero su actuación no se acotó al extenso ámbito de lo impreso: también fue realizador de «señalamientos urbanos» y creador de «máquinas inútiles». Asimismo, tuvo actuación como conferencista, como docente — durante años, fue profesor de dibujo e historia del arte en el Colegio Nacional de La Plata-, como gestor de exposiciones, como cronista de arte en diversos medios gráficos ${ }^{1}$. También cabe señalar que, durante toda su vida, se desempeñó como empleado judicial en los Tribunales Civiles del Poder Judicial de la provincia de Buenos Aires.

El fuerte anclaje que obra y vida de Vigo tuvieron con su ciudad natal —en la que desarrolló su actividad y desde donde logró conformar una red de intercambios de artistas internacionales - se proyecta en la actualidad en la preservación y difusión del corpus de obra y documentos que organizó a lo largo de su vida. En efecto, el Centro de Arte Experimental Vigo (CAEV) de La Plata tiene en custodia una gran cantidad de obras, libros, revistas, carpetas, fotografías, afiches, documentos mecanografiados, recortes de prensa, correspondencia, entre tantos otros materiales reunidos 
por ese artista. Situado a pocas cuadras de la plaza principal de la capital bonaerense, se trata una sencilla casa de una planta que, si bien puede pasar desapercibida para la mirada desprevenida de los transeúntes poco informados, alberga uno de los más fascinantes archivos de arte de la segunda mitad del siglo XX en la Argentina. En ese inagotable conjunto de materiales vinculados al universo creativo de Vigo - y en sintonía con el reconocido axioma vanguardista - allí el arte se fusiona con la vida. En efecto, mucho antes de instalarse la «fiebre archivística» contemporánea, el propio artista fue construyendo su propia serie de documentos que dan testimonio del desarrollo de su actividad artística, desde los inicios de su producción.

Desde 1953 hasta su fallecimiento, el 4 de noviembre de 1997, los registros de cada una de las acciones artísticas, de sus intercambios con otros artistas — como Julien Blaine, Paulo Brusky, Carlos Ginzburg, Claudia del Río, Clemente Padín, Juan Carlos Romero u Horacio Zabala, entre otros-, de su participación en exposiciones y publicaciones, de sus actuaciones como jurado de certámenes y premios, de sus aportes desde la crítica de arte o del ensayo como testimonio contemporáneo, toda ese cúmulo de "vida artística» se sucede en 37 cajas, cada una con su correspondiente referencia de año. En uno de sus característicos juegos de palabras, a partir de la sexta caja definió a ese conjunto de documentos y testimonios de su devenir artístico y biográfico con el nombre de Biopsia. La organización que, en forma progresiva, fue brindando Vigo a esos testimonios de su propia labor se mantiene en la actualidad a partir del contemporáneo criterio de conservación que sostiene la necesidad de preservar el orden original de los documentos.

Por expresa voluntad del artista, poco después de su fallecimiento el archivo de Vigo pasó a encontrarse bajo la custodia del Centro de Arte Experimental Vigo-Fundación Artes Visuales, conducido por Ana María Gualtieri; junto a ella, un entusiasta equipo de trabajo se desempeña desde entonces en este espacio autogestionado, desarrollando tareas de investigación, conservación, digitalización, fotografía y atención a las consultas del público. Mariana Santamaría, Mariana Fucks, Federico Santarsiero, Julio Lamilla y otros colaboradores integran en la actualidad el grupo que activa el CAEV. Legatario de la obra del artista platense, el CAEV se propone conservar y difundir su producción y los documentos por él reunidos durante tantas décadas de persistente labor cultural. En esta labor de difusión, la página web del CAEV resulta un recurso claramente complementario de la existencia del archivo físico platense. Tal como sostiene Mariana Fucks,

la página web del Centro Vigo mantiene la estructura básica en la que se divide el archivo «real»; al transportarla a una página web deseábamos que mantenga parte del espíritu de Vigo sin caer en el caos creativo. De esta manera el sitio cuenta con las mismas secciones que el archivo palpable. Allí están alojados los documentos digitalizados, los cuales se actualizan constantemente, sumando novedades ${ }^{2}$.

Gracias a la labor de preservación y difusión del CAEV, el registro de la dimensión múltiple de Vigo, ya reconocida en vida del artista, fue potenciada en los últimos ańos a partir de una serie de exhibiciones y publicaciones que, producto de investigaciones procedentes del campo académico y curatorial, abrevaron y se nutrieron de los materiales de este fascinante archivo (Dolinko, 2012; AAVV, 2016; Barisone, 2017; Bugnone, 2017). Afortunadamente, a pesar de las numerosas investigaciones en torno a su labor artística, la obra de Vigo pareciera aún resultar inagotable. 
Considerando la diversidad de poéticas, dispositivos y soportes que puso en juego, es posible considerar que existe una noción clave que articuló los múltiples proyectos de Vigo: la idea de intercambio o de participación dinámica y creativa. Ya en 1954 expuso en La Plata una serie de objetos móviles de madera que podían ser manipulados por los espectadores, apuntando en este conjunto inicial a la idea de familiaridad y conexión directa del público con la obra de arte (Centro de Arte Experimental Vigo 2008). Si este criterio de interacción constituyó uno de los principales ejes de la obra de Vigo, la edición de revistas y la difusión del grabado en madera tuvieron un rol ideológico y material significativo: para el artista, la xilografía posibilitaba un acercamiento «desacralizado» a la obra de arte frente a las limitaciones de otro tipo de producciones como la pintura o la escultura tradicionales. El grabado en madera fue, en efecto, una producción clave para Vigo tanto en lo que refiere a su propio trabajo artístico como en relación con los intercambios que estableció y los circuitos en los que intervino a lo largo de su trayectoria (Davis, 2004; Dolinko, 2008). La puesta en juego de esta antigua modalidad de impresión de origen popular le posibilitaba la multiplicación y amplia circulación de imágenes; así, la multiplicidad de la xilografía le permitía poner en cuestión - tanto en términos conceptuales como materiales - las limitaciones de la producción artística de ejemplar único.

Ya en sus primeras publicaciones — WC (1958) y $D R K W(1960)$ — Vigo había incluido xilografías, las cuales constituyeron una de las marcas diferenciales de su siguiente revista, Diagonal Cero (1962-1968), ocupando el espacio de presentación de la mayoría de las tapas y también impresas en sus páginas internas, ilustrando poesías, como imágenes autónomas o publicaciones anexas (Dolinko, 2012). También se destacó dentro de esta revista su edición de una serie de ocho cuadernillos de grabados en madera de distintos artistas publicados entre $1964 \mathrm{y}$ 1966. Tiempo después, los cuadernillos tomaron forma independiente a través de la edición de la serie "Xilógrafos de hoy» que Vigo continuó hasta 1969.

La producción gráfica de Vigo circulaba entonces por vías paralelas: tanto a través de estos cuadernillos y en las páginas de las revistas, como también en exposiciones de sus grabados en instituciones culturales. Así, el 21 de octubre de 1966 inauguró una muestra en la Biblioteca Benito Lynch de La Plata donde presentó «mono-xilografías a la témpera» - material que le otorgaba a la estampa una cualidad opaca y «empastada»— y «xilografías con resina». Como señaló contemporáneamente su colega Luis Pazos

la renovación en las artes plásticas adquiere en la actualidad un doble sentido: por un lado aparecen nuevas formas de expresión y por otro viejas técnicas cambian adaptándose a los nuevos conceptos. El segundo es el caso de los grabados expuestos. Vigo utiliza la tinta de imprenta, una prensa copiativa diseñada por él mismo, tacos de madera y trata a los grabados con un proceso especial de resina plastificando las figuras. [...] [la técnica de la estampa Los pájaros] insinúa la posibilidad de utilizar la tercera dimensión ${ }^{3}$.

Las preocupaciones de Vigo se desplegaban en esos tiempos en múltiples frentes de actuación, entre su producción de obras, la edición de estampas xilográficas propias y ajenas, la organización de exposiciones y la reflexión sobre la inscripción y circulación de esta producción en las instituciones culturales. Los alcances, complejidades y limitaciones del museo se presentaban, en este sentido, como uno de los focos de sus preocupaciones. Ya en 1964 había sostenido la necesidad de 
un Museo que se presente delante de nosotros constantemente. Unas galerías que perdieran el carácter de tales, que funcionaran más a la vista de ese dinámico andar del hombre por nuestras calles. [...] creo que no es necesario caer en la anti-dinámica de encerrar esos productos. En cuanto al interés popular, es un problema de educación visual. Cursos en bibliotecas populares, exposiciones [...] podrían dar una apertura interesantísima para abrir los grifos de ese interés popular ${ }^{4}$.

Este planteo anticipaba en forma implícita un programa de museo heterodoxo que iniciaría a fines de esa década.

En efecto, si la voluntad de posibilitar una difusión artística extendida y generar de ese modo una noción de comunidad tuvo un sentido fundamental dentro de los proyectos del artista $-\mathrm{y}$ si, como ya se ha señalado, estas aspiraciones se basaron en gran medida en el grabado en madera como recurso técnico-, entre las estrategias y acciones puestas en juego por Vigo cobró una dimensión particular su Museo de la Xilografía de La Plata, gestado a partir de un intercambio de ideas con el también artista platense Carlos Pacheco.

En 1968, las instituciones del campo cultural eran objeto de fuertes cuestionamientos por parte de grupos de artistas de la vanguardia local (Longoni y Mestman, 2000); Vigo era consciente de lo complejo de esta situación, y así explicitaba a fines de ese año que:

Fundar un Museo en nuestros días es contradictorio. Cuando el arte en su eterna rebusca clama la calle, la cotidianidad, la comunicación directa, es una acción gratuita hablar del «encierro» característico que el «MUSEO-Muselina» nos da.

Pero cobijar para no permitir las disgregaciones de obras, cuidar un «acervo» siempre será constante tarea.

La realidad que nos marca una línea, los acontecimientos que nos ubican, y las acciones que nos exigen, han hecho variar el concepto de Museo. Si éste abarca la suficiente dinámica, creo que popularizar es abrir las posibilidades de contacto [...]

EL MUSEO DE LA XILOGRAFÍA de LA PLATA, pretende captar esa DINÁMICA DE ACCIÓN CONTEMPORÁNEA y bregará como Institución actual, ser la cabeza de una nueva toma de posición para el enfrentamiento OBRA-COMUNIDAD.

Vigo suscribió esas palabras en ocasión de la presentación del Museo de la Xilografía en la Galería de arte del Cine Teatro Ópera de La Plata, con auspicio de la Biblioteca Max Nordau (un año antes, con el museo aún «en formación», había concretado la exposición Grabadores de La Plata en el Museo del Grabado, en Buenos Aires) $)^{5}$. Para ese momento, en su acervo se incluían obras de algunos artistas de Brasil, Uruguay, Chile, Suiza, Paraguay y Francia junto a la de argentinos como Pompeyo Audivert, Víctor Rebuffo, José Rueda, Abel Versacci y del propio Vigo. En la selección de nombres de artistas argentinos puede evidenciarse la fluida relación que Vigo mantuvo con otro emprendimiento contemporáneo y autogestivo basado en la circulación de xilografías: el Club de la Estampa de Buenos Aires; en efecto, la mayoría de esos artistas eran socios centrales de ese proyecto porteńo liderado por Albino Fernández (Dolinko, 2012).

El Museo de la Xilografía fue, de todos los proyectos de Vigo, aquél que tuvo mayor continuidad en el tiempo. El patrimonio inicial se fue acrecentando progresivamente a partir de donaciones y canjes de obras entre artistas argentinos 
y extranjeros, hasta llegar a incluir más de dos mil estampas que, además de las mayoritarias xilografías, también incluye monocopias, aguafuertes y técnicas mixtas, como así también matrices de madera legadas por algunos grabadores. Vigo prolongó la estrategia del canje hasta entrados los años noventa, cuando seguía solicitando o proponiendo intercambios de obras para el museo, excusándose porque «mi pasión por el grabado en madera rebasa a veces lo aconsejable» ${ }^{6}$.

Aunque su denominación apuntara a indicar lo contario, el Museo de la Xilografía no era una institución formal ni contaba con una sede física fija ni convencional. Se trataba, en verdad, de "cajas-móviles»: maletines de madera con manija y sujetadas por correas de tela o de cuero, con "paquetes» de estampas; a partir de esta condición de ubicuidad, el museo podía prestarse para ser exhibido en espacios culturales, instalarse en escuelas, clubes u otros ámbitos de sociabilidad comunitaria, como así también en casas particulares. El artista presentaba a estas intervenciones como "pequeńas exposiciones de rápido montaje. Con un simple elemento de sustentación (un atril, un pizarrón, un saliente donde colgar) se instala la muestra ambulante con idéntica sencillez a la de un puesto de feria». En muchas ocasiones, Vigo sumaba a la exposición de estampas una charla en la que divulgaba aspectos de la historia y la técnica xilográfica, poniendo así en acto la función pedagógica y de comunicación también fundante de este proyecto. Junto a la conformación de esta colección —y retomando estrategias iniciadas en los años sesenta—, Vigo emprendió la publicación de dos series de carpetas con grabados impresos con tacos originales, firmados y numerados, presentados como Ediciones del Museo de la Xilografía de La Plata. Entre 1973 y 1974, en paralelo a la edición de su revista Hexágono '71 (Bugnone 2017); concretó la colección «Xilógrafos de La Plata» (editada junto con «El león herbívoro», librería El Patio y la galería Libraco) que incluyó carpetas de Lidia Kalibatas, Sixto González, Adriana Grimaux y Graciela Gutiérrez Marx. Otra serie fue editada entre 1980 y 1989, con obras de Vigo, Hipólito Vieytes, Hebe Redoano, Enrique Arau, Carlos Pamparana, Hilda Paz, Laico Bou, Ludovico Pérez y Gustavo Larsen.

Como sostuviera su fundador, la labor cultural de difusión comunitaria de este museo «nacido bajo la necesidad de abrir nuevos canales» tenía como propósitos principales «llegar» $\mathrm{y}$ «mostrar», a la vez que «escapar a los encierros clásicos de las instituciones que atomizan el arte». Desarrollado por Vigo en forma ininterrumpida lo largo de tres décadas, el Museo de la Xilografía de La Plata fue reactivado luego del fallecimiento del artista en diversas instancias: por ejemplo, en diciembre de 2013, en el marco del evento Presión organizado por una formación de grabadores activos en La Plata.

Si se considera que las nociones de edición, circulación e intercambio fueron los ejes del programa del Museo de la Xilografía de La Plata, institución circulante albergada en cajas-valija de ecos duchampianos, el patrimonio de ese museo móvil que transportaba estampas originales y múltiples resulta un buen ejemplo de lo que, por esos tiempos, Vigo auguró como un «arte tocable» ${ }^{7}$. 


\section{Notas}

${ }^{1}$ Es destacable, por ejemplo, su lectura de las Experiencias 69 llevadas a cabo en el Centro de Artes Visuales del Instituto Torcuato Di Tella, en septiembre de 1969. Edgardo A. Vigo, «Exp.69-I/Di Tella», Ritmo, La Plata, 1969, p. 4 (recogido en Amigo, Dolinko y Rossi 2010).

${ }^{2}$ «Expedientes Vigo», Ramona, agosto de 2014, http://www.ramona. org.ar/node/53162

${ }^{3}$ Luis Pazos, «Vigo: la rebelión sin esperanza», El Día, La Plata, 28 de octubre de 1966. Efectivamente, Vigo pondría en juego el factor de la tridimensión en algunas de sus obras xilográficas de fines de esa década, como en Homenaje a Fontana.

${ }^{4}$ Mecanografiado, texto Vigo, Caja Biopsia, 1964, s/d. Archivo VigoCentro de Arte Experimental Vigo, La Plata (CEAV).

${ }^{5}$ La relación de Vigo con Oscar Pécora, fundador del Museo del Grabado, databa de varios años atrás. Vigo participó del programa de difusión del grabado impulsado por Pécora en octubre de 1963, a la vez que en algunas ocasiones se incluyó en Diagonal Cero publicidad de la Galería Plástica, propiedad de Pécora.

${ }^{6}$ Carta a Michael y Anette Groschopp, La Plata, 4 de marzo de 1986. Archivo CEAV.

${ }^{7}$ «Un arte tocable que se aleja de la posibilidad de abastecer a una "elite" que el artista ha ido formando a su pesar, un arte tocable que pueda ser ubicado en cualquier "hábitat" y no encerrado en Museos y Galerías. Un arte con errores que produzca el alejamiento del exquisito». «Hacia un arte tocable», La Plata, 1968-1969.

\section{Referencias bibliográficas}

AA.VV. (2016). Edgardo-Antonio Vigo. Usina permanente de caos creativo. Obras 1953-1997. Buenos Aires: Museo de Arte Moderno de Buenos Aires. Amigo, R., Dolinko, S. y Rossi, S. (eds.) (2010). Palabra de artista. Escritos sobre arte argentino, 1961-1981. Buenos Aires: Fundación Espigas-Fondo Nacional de las Artes.

Barisone, O. (2017). Experimentos poéticos opacos. Biopsias malditas: del invencionismo argentino a la poesía visual (1944-1969). Buenos Aires: Corregidor.

Bugnone, A. (2017). Edgardo Vigo. Arte, política, vanguardia. La Plata: Malisia.

Centro de Arte Experimental Vigo (2008), Maquinaciones. Edgardo Antonio Vigo: trabajos 1953-1962. Buenos Aires: Centro Cultural de España en Buenos Aires, Museo Provincial de Bellas Artes, Córdoba, Museo Provincial de Bellas Artes, La Plata.

Davis, F. (2004). Edgardo-Antonio Vigo. Xilografías y ediciones (1962-1972). En Edgardo-Antonio Vigo. Xilografias y ediciones (19621972). Buenos Aires, Museo Nacional del Grabado.

Dolinko, S. (2008). Circulación de xilografías y poesías latinoamericanas a través de la Diagonal Cero de Edgardo Antonio Vigo. En Drien, M., 
Guzmán, F. y Martínez, J.M. (ed.), América: territorio de transferencias (Pp. 245-254). Valparaíso: Facultad de Humanidades de la Universidad Adolfo Ibáńez y Museo Histórico Nacional.

(2012) Arte plural. El grabado entre la tradición y la experimentación. Buenos Aires: Edhasa.

Herrera, M.J. (2004). Vigo en (con) texto. En Besoytaorube, D. (ed.), Edgardo-Antonio Vigo. Buenos Aires: Espacio Fundación Telefónica.

Longoni, A. y Mestman, M. (2000). Del Di Tella a "Tucumán Arde». Vanguardia artística y politica en el '68 argentino. Buenos Aires: Ediciones El cielo por asalto.

\section{Dolinko, Silvia}

«El grabado en madera como arte tocable. Edgardo Antonio Vigo y el Museo de la Xilografía de La Plata». El hilo de la fábula. Revista anual del Centro de Estudios Comparados (18), 213-220.

Fecha de recepción: $12 \cdot 03 \cdot 18$

Fecha de aceptación: $20 \cdot 04 \cdot 18$ 